\title{
Possible venous air embolism during open eye surgery in a child
}

\author{
[Possible embolie gazeuse veineuse lors d'une chirurgie à ail ouvert chez
}

un enfant]

Pierre Ruest MD FRCPC, Maryam Aroichane MD FRCSC, Ghassan Cordahi MD, Nathalie Bureau BSN CCRC

Purpose: Although venous air embolism is a well recognized complication within most surgical subspecialties, it has only been reported recently during eye surgery in one adult, and never before in a child. We describe the case of a 17-month-old boy who sustained a possible air embolism during repair of an open trauma of his right eye.

Clinical features: A vitrectomy through the pars plana with air-fluid exchange of the posterior chamber was performed under general anesthesia to remove a foreign body which had impaled the optic nerve. A few minutes after removal of the foreign body, a notable decrease in end-tidal $\mathrm{CO}_{2}$, oxygen saturation and arterial blood pressure occurred, requiring administration of a high inspired oxygen fraction and vasopressors. Venous air embolism was strongly suspected after other causes of a decrease of end-tidal $\mathrm{CO}_{2}$ and hypoxemia had been excluded. An arterial blood gas confirmed hypoxemia and respiratory acidosis.

Conclusion: Although venous air embolism is a rare complication of eye surgery, it should nevertheless be considered as a possible complication during air-fluid exchange vitrectomy in children.

CAN J ANESTH 2007 / 54: $10 /$ pp 840-844

Objectif: Bien que l'embolie gazeuse veineuse soit une complication bien connue dans la plupart des spécialités chirurgicales, celle-ci n'a été que récemment rapportée pendant une chirurgie oculaire chez un adulte, et jamais auparavant chez un enfant. Nous décrivons le cas d'un garçon de 17 mois qui a possiblement subi une embolie gazeuse pendant la réparation d'un trauma ouvert de son œil droit.
Éléments cliniques : Une vitrectomie à travers la pars plana avec un échange gaz-fluide de la chambre postérieure a été effectuée sous anesthésie générale afin d'extraire un corps étranger qui avait empalé le nerf optique. Quelques minutes après l'extraction du corps étranger, une réduction considérable du $\mathrm{CO}_{2}$ télé-expiratoire, de la saturation d'oxygène et de la pression artérielle est survenue, nécessitant l'administration d'une fraction élevée d'oxygène inspiré et de vasopresseurs. Après avoir exclu d'autres causes de la réduction $\mathrm{du} \mathrm{CO}_{2}$ télé-expiratoire et de l'hypoxémie, une embolie gazeuse veineuse a été fortement suspectée. Un gaz artériel a confirmé l'hypoxémie et l'acidose respiratoire.

Conclusion : Bien que l'embolie gazeuse veineuse soit une complication rare des chirurgies de l'œil, elle devrait néanmoins être considérée comme une complication possible durant une vitrectomie par échange gaz-fluide chez les enfants.

I NTRAOPERATIVE venous air embolism (VAE) is a well recognized complication associated with numerous procedures performed in almost all surgical specialties. ${ }^{1}$ However the real incidence of VAE is probably underestimated since its diagnosis depends on the sensitivity of detection of methods used. Moreover, many cases of VAE are subclinal. It may indeed occur every time the site of the surgery is higher than the heart as in neurosurgical procedures done in the sitting position. Although VAE has been reported only recently during cataract surgery in one adult ${ }^{2}$ and never before in children, it may complicate ophthalmic surgery performed in the supine position in young children, since the head is relatively larger compared to the rest of the body in that age group, and above the level of the heart.

From the Department of Anesthesiology, Centre hospitalier universitaire Sainte-Justine, Montreal, Quebec, Canada.

Address correspondence to: Dr. Pierre Ruest, Department of Anesthesiology, CHU Sainte-Justine, 3175 Cote Sainte-Catherine Road, Montreal, Quebec H3T 1C5, Canada. Phone: 514-345-4931, ext. 4733; Fax: 514-345- 4798; E-mail: pierre.ruest.hsj@ssss.gouv.qc.ca

Financial support: Department of Anesthesiology, CHU Sainte-Justine, Montreal, Quebec, Canada.

Accepted for publication June 14, 2007.

Revision accepted July 16, 2007. 


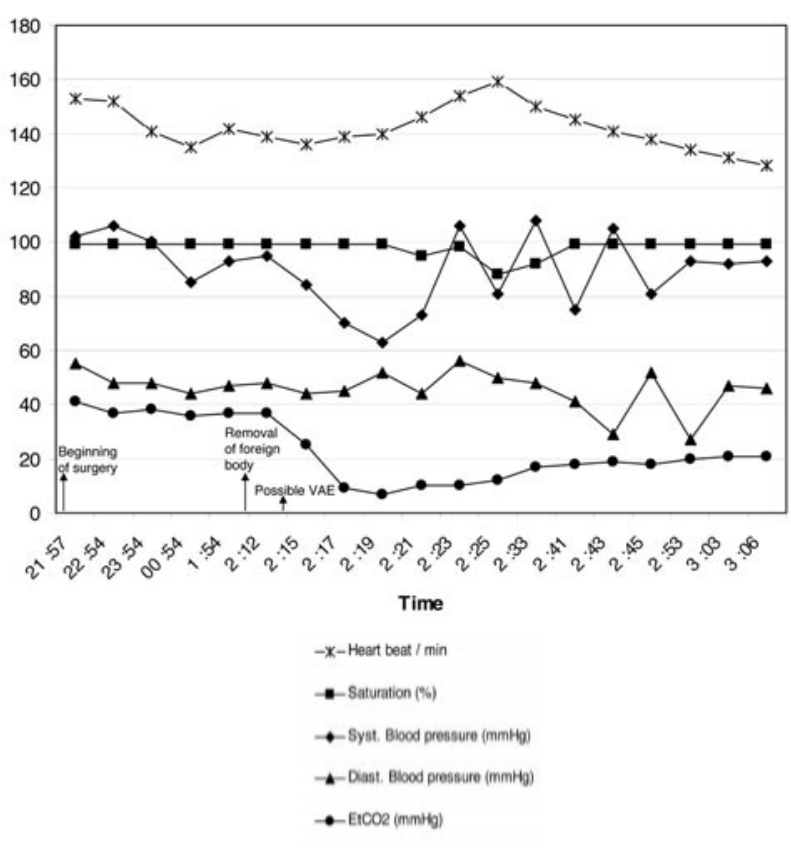

FIGURE Hemodynamic variables, oxygen saturation, and end-tidal $\mathrm{CO}_{2}\left(\mathrm{ETCO}_{2}\right)$ values at critical time points from induction of anesthesia to the end of surgery.

Written consent for publication of this report was obtained from the parents of the child.

\section{Case report}

A 17-month-old boy with no pre-existing medical condition and with no allergies sustained a severe eye penetrating injury of his right eye. The metallic spring of his mother's hair slide was propelled at high velocity into his right eye, through the cornea, anterior chamber, iris, and crystalline lens, impaling the optic nerve. Surgery was planned on an urgent basis.

Following application of routine monitors, and after pre-oxygenation a rapid sequence induction with the Sellick maneuver was performed with administration of atropine, propofol, fentanyl and rocuronium. The trachea was intubated easily and the child's lungs were ventilated using a volume-controlled mode to maintain normocapnia with an air/oxygen mixture to obtain an $\mathrm{F}_{\mathrm{I}} \mathrm{O}_{2}$ of 0.4 .

Using a Millenium ${ }^{\mathrm{TM}}$ Microsurgical system (Bausch \& Lomb Inc., Rochester, NY, USA) designed for use in both anterior and posterior segment surgeries, a pars plana vitrectomy was performed with removal of the vitreous and preretinal hemorrhages. The posterior hyaloid was detached during the vitrectomy. The
TABLE Laboratory results

\begin{tabular}{|c|c|c|c|c|c|c|}
\hline Time & $\begin{array}{l}\mathrm{F}_{\mathrm{I}} \mathrm{O}_{2} \\
(\%)\end{array}$ & $\begin{array}{l}\text { Arterial } \\
p H\end{array}$ & $\begin{array}{l}\text { Arterial } \\
\mathrm{pCO}_{2} \\
(m m \mathrm{Hg})\end{array}$ & $\begin{array}{l}\text { Arterial } \\
\mathrm{pO}_{2} \\
(m m \mathrm{Hg})\end{array}$ & $\begin{array}{l}\mathrm{EtCO}_{2} \\
(\mathrm{mmHg})\end{array}$ & $\begin{array}{l}\text { Bicarbonate } \\
\left(m m o l \cdot L^{-1}\right)\end{array}$ \\
\hline 45 & 100 & 7.163 & 57.6 & 64.2 & 10 & 17.1 \\
\hline 3:06 & 100 & 7.240 & 46.6 & 215.0 & 22 & 18.3 \\
\hline
\end{tabular}

fundus examination revealed a branch of retinal artery occlusion and a branch of retinal vein occlusion in the nasal parts of the retina superiorly and inferiorly. Endolaser was performed with the EndoProbe to treat the ischemic part of the retina, as well as the peripheral retina on a $360^{\circ}$ plane.

In order to prevent bleeding from central retinal vessels during removal of the intraocular foreign body, an intraocular tamponade was induced by raising the infusion pressure to $120 \mathrm{~cm} \mathrm{H}_{2} \mathrm{O}$. This was followed by an air-fluid exchange. A the end of the surgery, only a few minutes after removal of the foreign body, end-tidal $\mathrm{CO}_{2}\left(\mathrm{EtCO}_{2}\right)$ decreased sharply from 37 to $10 \mathrm{mmHg}$, saturation from 99 to $88 \%$, and systolic blood pressure from 100 to $65 \mathrm{mmHg}$ (Figure). Pulmonary auscultation revealed a normal bilateral vesicular murmur with no evidence of bronchospasm or secretion. There was no increase in ventilatory pressure. After excluding possible mechanical problems with ventilation, the possibility of VAE was strongly suspected. $\mathrm{F}_{1} \mathrm{O}_{2}$ was increased to $100 \%$, the intravenous line was checked for possible infusion of air and the intraocular air-fluid exchange was stopped by the surgeon. Administration of four doses of ephedrine (1 $\mathrm{mg} i v$ ) was necessary to restore adequate arterial blood pressure. End-tidal $\mathrm{CO}_{2}$ remained below $25 \mathrm{mmHg}$ for the next two hours and arterial blood gas analysis confirmed a large $\mathrm{EtCO}_{2}-\mathrm{PaCO}_{2}$ gradient (Table). A chest $x$-ray showed no sign of pulmonary aspiration but bilateral perihilar infiltrates compatible with mild pulmonary edema were present, and resolved completely the next day. The patient was admitted to the intensive care unit approximately two hours after the event. An echocardiogram ruled out a septal defect of the heart. After discontinuation of sedation, the child awoke promptly and his trachea was extubated eight hours after the initial event with no neurological deficit. He was discharged from hospital the next day.

\section{Discussion}

The incidence of VAE in children undergoing neurosurgical procedures varies from 26 to $82.6 \% .^{3-5}$ The wide variability in reporting frequencies of this 
complication may be ascribed, at least in part, to the different means of detecting VAE and the relatively small number of children included in these studies. Nevertheless, in the largest pediatric retrospective study of children undergoing neurosurgery in the sitting position $(n=407)$, Harrison et al. ${ }^{6}$ reported a $9.3 \%$ incidence of VAE, as detected by a decrease in $\mathrm{EtCO}_{2}>3 \mathrm{mmHg}$, and a $20 \%$ incidence of secondary hypotension defined as a $10 \%$ or more drop in blood pressure. The incidence of VAE is not influenced by the ASA physical status. ${ }^{\text {? }}$

The lower incidence of VAE, as detected by Doppler ultrasonography in children $(9.3-37 \%)^{4,6}$ compared to adults $(7-50 \%)$ may be explained in part by the relatively high dural sinus pressure in children compared to adults. ${ }^{8}$ It is recognized that an equivalent air bubble size would theoretically have a more profound impact in children. Although the lethal volume of air is estimated to be 200 to $300 \mathrm{~mL}$ in adults, ${ }^{9}$ a slower rate of air entrainment $(0.05$ to 0.30 $\left.\mathrm{mL} \cdot \mathrm{kg}^{-1} \cdot \mathrm{min}^{-1}\right)^{10}$ may be tolerated due to the time constant for gas dissipation via the large surface area of the alveoli. The ability to tolerate VAE appears to require intact endogenous nitric oxide production mechanisms. ${ }^{11}$

Entrainment of air into the pulmonary arterioles may induce reflex pulmonary bronchoconstriction and vasoconstriction through different mechanisms; release of endothelin-1, ${ }^{12}$ platelet aggregation, and release of platelet activator inhibitor, which may precipitate a systemic inflammatory syndrome. ${ }^{12,13} \mathrm{~A}$ large air embolus may also create an air-lock within the right ventricle obstructing pulmonary blood flow. Secondary pulmonary hypertension may lead to a left shift of the interventricular septum, a diminished preload of the left ventricle, diminished cardiac output and systemic hypotension. The increase in dead space produces hypoxemia and a discrepancy between $\mathrm{PaCO}_{2}$ and $\mathrm{EtCO}_{2}$. The subsequent increased pulmonary vascular permeability may lead to pulmonary edema and aggravate hypoxemia. Although this patient did not experience any electrocardiogram (ECG) changes, large P waves are frequently observed in association with air embolism, which are usually the first ECG alterations to be noted, followed by tachyarrhythmia and even ST-T changes.

Once other potential causes have been excluded, VAE caused by entrainment of air through the central retinal vein appears to be the most plausible explanation for the abrupt decrease in $\mathrm{PaCO}_{2}$, hypoxemia and hemodynamic instability observed in our patient. Anaphylaxis was also considered, but since there was no sign of bronchospasm, no urticarial rash and no temporal association with drug administration, specific IgE concentrations and plasma tryptase were not measured. Venous air embolism may be the result not only of anterograde venous air entrainment but it may also follow retrograde venous and arterial routes and even epidural routes. ${ }^{14}$ A negative pressure gradient or positive pressure insufflations of gas or a liquid-gas mixture, as in the case described, may cause

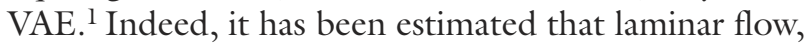
inflated with $\Delta P$ of $20 \mathrm{mmHg}$ (air inflation pressure $40 \mathrm{mmHg}$ - intraocular pressure $20 \mathrm{mmHg}$ ) through a $20-\mathrm{G}$ inflation cannula could result in a theoretical flow of $1600 \mathrm{~mL} \cdot \mathrm{min}^{-1} .^{2}$ This is well above the lethal rate of air entrainment, although the flow created by the air-fluid exchange within the eye is not laminar.

Several methods exist to detect VAE with varying degrees of specificity and sensitivity. The esophageal stethoscope is not a sensitive monitoring for VAE. The classical millwheel murmur was not present in our patient. Indeed it can be heard in only $5 \%$ of patients ${ }^{7}$ and does not occur unless air enters the venous circulation at a rate of $1.9 \mathrm{~mL} \cdot \mathrm{kg}^{-1} \cdot \mathrm{min}^{-1}$ Pulse oximetry and airway pressure monitoring are neither sensitive nor reliable indicators of VAE. ${ }^{15}$ End-tidal $\mathrm{CO}_{2}$ monitoring has a threshold sensitivity of $0.4 \mathrm{~mL} \cdot \mathrm{kg}^{-1} \cdot \mathrm{min}^{-1}$ which is less than that of ultrasound Doppler and transesophageal echocardiography. Precordial ultrasound Doppler is the most sensitive non-invasive monitoring tool to detect VAE and is sensitive to within $0.05 \mathrm{~mL} \cdot \mathrm{kg}^{-1}$, although it provides non-quantitative monitoring. A Doppler signal can be obtained more reliably and be as sensitive at detecting VAE if positioned at the left parasternal border $v s$ the right parasternal border. Transesophageal echocardiography is the most sensitive monitoring modality for detecting microbubbles $\left(0.02 \mathrm{~mL} \cdot \mathrm{kg}^{-1}\right)$ in the right and left cardiac chambers, ${ }^{16}$ but remains an invasive and expensive monitor that requires substantial operator training.

We performed a contrast echocardiogram in the immediate postoperative period to rule out any intracardiac septal defects, ${ }^{4,17}$ since a patent foramen ovale (PFO) can be present in about $20 \%$ of the normal population and paradoxical air embolism usually occurs following more severe VAE. ${ }^{16}$ Moreover, the presence of PFO is not an absolute prerequisite for a paradoxical systemic air embolism. Indeed, air bubbles smaller than $10 \mu$ in the right side of the heart may reach the systemic circulation through pulmonary and pleural capillaries, bronchial veins, pulmonary arteriovenous fistulae, venae cordis minimae or anterior cardiac veins. ${ }^{18}$ Cerebral computed tomography scans can be used to confirm cerebral air embolism, although a normal computed tomography scan cannot 
rule out a cerebral air embolism and should not delay specific treatment (hyperbaric oxygen therapy).

Successful management of VAE implies early detection and prevention of further venous air entrainment. Nitrous oxide administration, if used, must be discontinued at once and not reintroduced since it increases the volume of the air bubbles. Inspired oxygen fraction should be increased to $100 \%$ to optimize oxygenation and to decrease the size of the air embolus. Repositioning the patient in the left lateral position (Durant maneuver) to confine the air embolus away from the right ventricle outlet, or in the Trendelenburg position, has no clear benefit. ${ }^{19}$

Although large airway pressure variations should be avoided, positive pressure ventilation is desirable. Administration of positive end expiratory pressure (PEEP) has been used without convincing evidence of any beneficial effect and should be used only to improve oxygenation. Bilateral compression of the jugular veins significantly increases the sagittal sinus pressure $^{8}$ but cannot be recommended as part of the initial treatment of VAE during eye surgery ${ }^{1}$ Elevated venous pressure may promote collection of air bubbles in the superior vena cava and even in the internal jugular veins reducing the risk of massive air embolism. ${ }^{20}$ This can be accomplished by fluid administration.

Dobutamine, epinephrine and norepinephrine have all been used successfully for hemodynamic support. Cardiopulmonary resuscitation must be instituted at once if cardiovascular collapse occurs. Moreover, external cardiac massage would have the capacity of displacing air within the cardiac chambers. ${ }^{21}$ Air can be retrieved from the central venous line in only $6 \%$ of the cases. Efficiency of air retrieval depends on the type and position of the catheter used (mono-orifice vs multi-orifice catheter), patient position and orientation of the heart. Their insertion during the acute phase of a VAE is not recommended and should not delay resuscitation maneuvers.

Hyperbaric oxygen therapy (HOT) has been advocated for the management of VAE complicated with arterial air embolism. ${ }^{22}$ Its benefits are increased if instituted within six hours after the occurrence of a VAE, but success associated with delayed administration has also been reported..$^{23}$ Administration of repetitive HOT is recommended until no further improvement is observed.

Perfluorocarbons are artificial oxygen-carrying compounds with extremely high solubility for gases that have been studied as blood substitutes used to reduce the volume of air bubbles and to improve outcome of cerebral air embolisms. ${ }^{24}$ In cerebral air embolism animal models, prophylactic administration of lidocaine reduced depressant effects of gas embolism on somatosensory evoked potentials and attenuated the increase in intracranial pressure. ${ }^{25}$

In conclusion, symptomatic VAE is a rare complication of pars-plana vitrectomy and air-fluid exchange, although the exact incidence of air entrainment is not known. Nevertheless, it should be considered in the differential diagnosis of a patient who experiences an abrupt decrease of $\mathrm{EtCO}_{2}$, arterial desaturation, arrhythmias or hemodynamic instability. In case of delayed emergence from anesthesia, neurological abnormalities or signs of myocardial ischemia, HOT should be strongly considered as soon as the patient has been stabilized. End-tidal $\mathrm{CO}_{2}$ is sufficiently sensitive for VAE detection during vitrectomy that routine use of more invasive monitoring is not justified, although precordial ultrasound monitoring may be considered in procedures at higher risk of intraocular bleeding.

\section{References}

1 Mirski MA, Lele AV, Fitzsimmons L, Toung TJ. Diagnosis and treatment of vascular air embolism. Anesthesiology 2007; 106: 164-77.

2 Ledowski T, Kiese F, Jeglin S, Scholz J. Possible air embolism during eye surgery. Anesth Analg 2005; 100: 1651-2.

3 Cucchiara RF, Bowers B. Air embolism in children undergoing suboccipital craniotomy. Anesthesiology 1982; 57: 338-9.

4 Fuchs G, Schwarz G, Stein J, Kaltenbock F, Baumgartner A, Oberbauer RW. Doppler color-flow imaging: screening of a patent foramen ovale in children scheduled for neurosurgery in the sitting position. J Neurosurg Anesthesiol 1998; 10: 5-9.

5 Faberowski LW, Black S, Mickle JP. Incidence of venous air embolism during craniectomy for craniosynostosis repair. Anesthesiology 2000; 92: 20-3

6 Harrison EA, Mackersie A, McEwan A, Facer E. The sitting position for neurosurgery in children: a review of 16 years' experience. Br J Anaesth 2002; 88: 12-7.

7 Bithal P, Dash HH, Vishnoi N, Chaturvedi A. Venous air embolism: does the site of embolism influence the hemodyamic changes? Neurol India 2003; 51: 370-2.

8 Iwabuchi T, Sobata E, Ebina K, Tsubakisaka H, Takiguchi $M$. Dural sinus pressure: various aspects in human brain surgery in children and adults. Am J Physiol 1986; 250(3 pt 2): H389-96.

9 Toung TJ, Rossberg MI, Hutchins GM. Volume of air in a lethal venous air embolism. Anesthesiology 2001; 94: 360-1.

10 Butler BD, Hills BA. Transpulmonary passage of venous air emboli. J Appl Physiol 1985; 59: 543-7.

11 Agvald P, Adding LC, Nilsson KF, Gustafsson LE, 
Linnarsson D. Increased expired $\mathrm{NO}$ and roles of $\mathrm{CO}_{2}$ and endogenous NO after venous gas embolism in rabbits. Eur J Appl Physiol 2006; 97: 210-5.

12 Tanus-Santos JE, Gordo WM, Udelsmann A, Cittadino $M H$, Moreno $M J r$. Nonselective endothelin-receptor antagonism attenuates hemodynamic changes after massive pulmonary air embolism in dogs. Chest 2000; 118: 175-9.

13 Kapoor T, Gutierrez G. Air embolism as a cause of the systemic inflammatory response syndrome: a case report. Crit Care 2003; 7: R98-100.

14 Karaosmanoglu D, Oktar SO, Arac M, Erbas G. Case report: Portal and systemic venous gas in a patient after lumbar puncture. Br J Radiol 2005; 78: 767-9.

15 Dash HH, Bithal PK, Joshi S, Saini SS. Airway pressure monitoring as an aid in the diagnosis of air embolism. J Neurosurg Anesthesiol 1993; 5: 159-63.

16 Mammoto T, Hayashi $\Upsilon$, Ohnishi $\Upsilon$, Kuro M. Incidence of venous and paradoxical air embolism in neurosurgical patients in the sitting position: detection by transoesophageal echocardiography. Acta Anaesthesiol Scand 1998; 42: 643-7.

17 Brickner ME, Grayburn PA, Fadel B, et al. Detection of patent foramen ovale by Doppler color flow mapping in patients undergoing cardiac catheterization. Am J Cardiol 1991; 68: 125-9.

18 Tommasino C, Rizzardi R, Beretta L, Venturino M, Piccoli $S$. Cerebral ischemia after venous air embolism in the absence of intracardiac defects. J Neurosurg Anesthesiol 1996; 8: 30-34.

19 Geissler HJ, Allen SJ, Mehlhorn U, Davis KL, Morris $W P$, Butler BD. Effect of body repositioning after venous air embolism. An echocardiographic study. Anesthesiology 1997; 86: 710-7.

20 Pfitzner J, McLean AG. Venous air embolism and active lung inflation at high and low CVP: a study in «upright» anesthetized sheep. Anesth Analg 1987; 66: 1127-34.

21 Yeh PA, Chen HP, Tsai YC, Lin YJ, Lin YC. Successful management of air embolism-induced ventricular fibrillation in orthotopic liver transplantation. Acta Anaesthesiol Taiwan 2005. 43: 243-6.

22 LeDez KM, Zbitnew G. Hyperbaric treatment of cerebral air embolism in an infant with cyanotic congenital heart disease. Can J Anesth 2005; 52: 403-8.

23 Mader JT, Hulet WH. Delayed hyperbaric treatment of cerebral air embolism: report of a case. Arch Neurol 1979; 36: 504-5.

24 Yoshitani K, de Lange F, Ma Q Grocott HP, Mackensen $G B$. Reduction in air bubble size using perfluorocarbons during cardiopulmonary bypass in the rat. Anesth Analg 2006; 103: 1089-93.

25 Dutka AJ, Mink R, McDermott J, Clark JB, Hallenbeck
$J M$. Effect of lidocaine on somatosensory evoked response and cerebral blood flow after canine cerebral air embolism. Stroke 1992; 23: 1515-20. 